\title{
Influence of furniture arrangement on airflow distribution in open concept passive houses
}

\author{
Doru Daniel Sabie ${ }^{1}$, and Adrian-Gabriel Ghiaus, ${ }^{1, *}$ \\ ${ }^{1}$ Technical University of Civil Engineering of Bucharest, 021414 Bucharest, Romania
}

\begin{abstract}
This paper presents the analysis of airflow distribution in an open space room by means of CFD numerical simulation having as case study a pre-certified passive house, located in Cluj-Napoca. The ventilation system comprises two rectangular inlets, located on the floor near the glazing and six exhaust grilles of circular cross section located at the opposite side, at the kitchen's ceiling. An area of interest that represents the simulation/computation domain was selected. Numerical modeling was done through a commercial software, based on the finite element method that simulates a series of interconnected phenomena encountered in the field of applied engineering. Dry air was considered the fluid environment in the computing domain with thermo-physical properties taken from the program database. No slip boundary conditions were used for all the walls, volume flow rate of $215 \mathrm{~m}^{3} / \mathrm{h}$ was specified for the inlets and exhaust nozzles were considered as open boundary. The following simplifying working hypotheses were established: stationary regime, incompressible fluid, constant temperature, isothermal jet, adiabatic system without internal heat sources, disregarding of mass forces. Airflow distribution analysis was performed for two distinct configurations: without furniture and in the presence of furniture. Simulation domain was divided into a large number of finite elements of variable size having a higher density near the boundary areas resulting tens of thousands of nodes. The purpose of the simulation was to evaluate the influence of furniture on the distribution of air currents in the occupied areas with direct impact on the occupants' comfort. Upon the comparative analysis for the two distinct cases, based on the distribution of streamlines, pressure and velocity vectors, the furniture's influence areas, the stationary areas and the air recirculation areas were identified.
\end{abstract}

\section{Introduction}

In the modern world where he lives and carries out his daily activities, man is in continuous interaction with the environment. Under various actions of physiological and psychological sources, he constantly seeks complex technological solutions to "secure" the quality of the environment in which he develops his creative abilities.

The quality of the environment is appreciated by the value of thermal comfort parameters, chemical composition and purity of the air, as well as other factors such as illumination and noise level, air ionization degree, aesthetics, etc.

Systematic research of passive houses in the European projects coordinated by PHI (Passive House Institute) $[1,2,3]$, has shown that for a proper distribution of fresh air in all working rooms and for a sufficient volume of air extracted from the high humidity rooms, the most suitable ventilation system is the one with heat recovery. Fresh air should be provided to living, working and sleeping rooms $[4,5]$.

The criteria for assessing the energy performance of passive houses impose very high requirements on the ventilation system as regards the fresh air flow rate in order to meet the indoor air quality requirements for occupant hygiene and health, as well as the hydrothermal stability of the building, effectively managing

\footnotetext{
*Corresponding author: adrian.ghiaus@utcb.ro
}

heat inputs generated by internal "sources" and by environment. [6,7]

A very sensitive aspect of the ventilation systems specific to passive buildings is the provision of an internal air refresh rate that simultaneously satisfies two aspects: ensuring indoor comfort and minimizing heat loss through controlled mechanical ventilation [8].

The paper aims to analyze how the presence of furniture would have a significant influence on the distribution of air currents within the living space.

This paper presents the results obtained in a numerical modeling and numerical simulation assisted by the specialized software COMSOL Multiphisycs [9] concerning the influence of furniture on the qualitative and quantitative distribution of air current distribution within the simulation area of a pre-tested passive house.

\section{Materials and methods}

\subsection{House description and facilities}

The investigated building, located in Cluj-Napoca, Romania, is a residential house having an useful area of $276 \mathrm{~m}^{2}$. From a constructive point of view, although a concrete resistance structure was originally envisaged in the project, the final adopted solution was with polystyrene formworks filled with monolith reinforced 
concrete. For the outside finishing of the building, materials with different textures were used, the ground floor is dominated by stone and wooden plywood and the first floor is made of white frame around the spaces surrounding the south and north walls, plated with horizontally wooden rows, carpentry coated with aluminum painted in gray anthracite, appearing as small accents on the facades.

Large glazed surfaces, mostly oriented to the south, provide both the required solar input and natural light while reducing the visual barrier between the indoor and outdoor. The reduced number of gaps on the main façade from the north reduces heat loss and gives privacy to the residents.

The characteristic parameters of the components of the building envelope are shown in a representative vertical section in Figure 1.

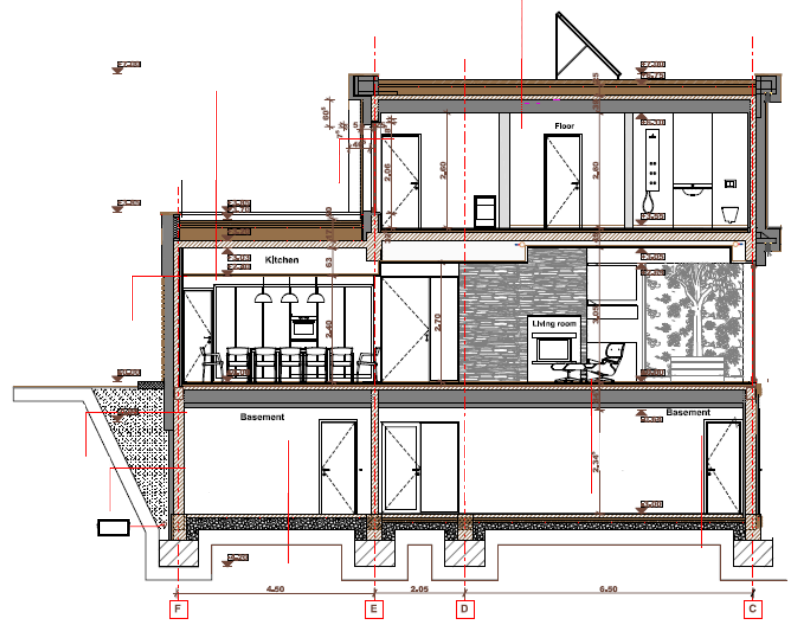

Fig. 1. Overview of the vertical section of the house.

In the preliminary tests performed by the Passive House Institute (PHI) specialists, it was determined that the annual energy demand for heating is $12 \mathrm{KWh} / \mathrm{m}^{2}$ and the required annual primary energy is $58 \mathrm{KWh} / \mathrm{m}^{2}$.

In winter, the demand for heating the passive house will be achieved by means of a fireplace located in the living room with an air-to-air heat exchanger and during the transit and summer periods the demand for domestic hot water with the help of the solar panels placed on the the green roof. Hot water will be stored in two hot water tanks located at the basement.

The heat recovery ventilation system, Figure 2, will provide fresh air that will be preheated both in summer and in winter by means of a closed loop geothermal collector.

The closed-loop geothermal collector system is a horizontal serpentine made of a polyethylene pipe located at a depth of approximately 4 meters connected to the heat exchanger ventilation system.

The ventilation system has the following features: $320 \mathrm{~m}^{3} / \mathrm{h}$,

volume flow rate of the air ventilation unit: 50

recovery rate - heat exchanger: $84 \%>80 \%$, electricity demand: $0.31 \mathrm{Wh} / \mathrm{m}^{3}<0.45 \mathrm{Wh} / \mathrm{m}^{3}$, noise level $28 \mathrm{~dB}(\mathrm{~A})<30 \mathrm{~dB}(\mathrm{~A}),[10]$

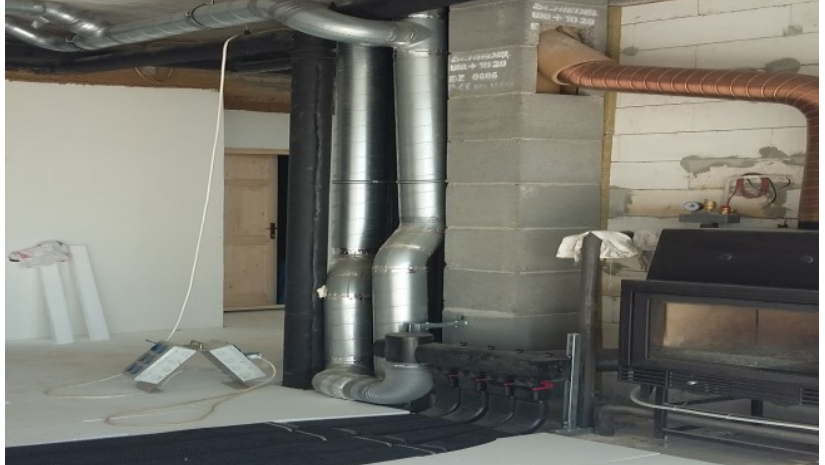

Fig. 2. The ventilation system.

\subsection{Computation domain}

From the architectural design of the passive house, a control area/volume located at the ground floor of the building was selected for the simulation domain, as it's shown in Figure 3. Thus, the air volume of the analyzed domain is $278 \mathrm{~m}^{3}$ when no furniture is in place and $271 \mathrm{~m}^{3}$ with furniture proposed by the architect.

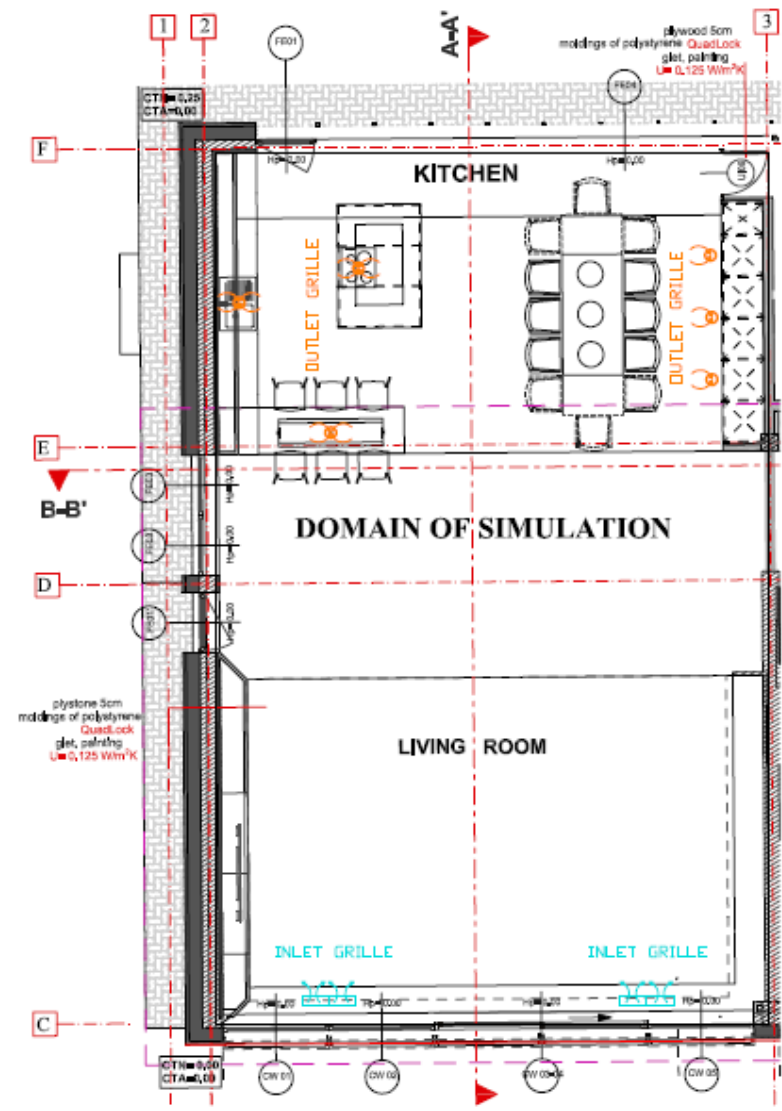

Fig. 3. The domain of simulation.

In the first instance, the thermo-physical properties of the fluid environment in the field of calculation, considered as dry air, were setup with the following values:

- temperature, $\mathrm{T}_{20}=293.15 \mathrm{~K}$,

- density, $\rho_{\text {air }}=1.205 \mathrm{~kg} / \mathrm{m}^{3}$,

- kinematic viscosity, $v_{20}=15.1 \cdot 10^{-6} \mathrm{~m}^{2} / \mathrm{s}$,

- dynamic viscosity, $\eta_{20}=18.12 \cdot 10^{-6} \mathrm{~N} \cdot \mathrm{s} / \mathrm{m}^{2}$,

- pressure, $p=101325 \mathrm{~N} / \mathrm{m}^{2}$. 


\subsection{Conditions of uniqueness}

The boundary conditions were defined as NO SLIP, the air layer in contact with the wall surface is adherent to it, i.e. $\mathrm{v}_{0}=0 \mathrm{~m} / \mathrm{s}$. Other uniqueness conditions refer to refresh rate of air, $\mathrm{n}_{\mathrm{a}}=0,6 \mathrm{~h}^{-1}$ and balanced ventilation rate, $V_{i}=V_{e}$.

In accordance with the legislation in the field of ventilation, three cases concerning the values of the air jet velocity and volume flow rate introduced into the room were analyzed:

- Case 1: $\mathrm{v}_{1}=0.1 \mathrm{~m} / \mathrm{s}, \mathrm{V}_{1}=86 \mathrm{~m}^{3} / \mathrm{h}$,

- Case $2: \mathrm{v}_{2}=0.2 \mathrm{~m} / \mathrm{s}, \mathrm{V}_{2}=172 \mathrm{~m}^{3} / \mathrm{h}$,

- Case 3: $\mathrm{v}_{3}=0.5 \mathrm{~m} / \mathrm{s}, \mathrm{V}_{3}=215 \mathrm{~m}^{3} / \mathrm{h}$.

\subsection{Simulation model}

Based on the data taken from the site and the architectural design of the passive house, the geometry of the model (study) subjected to simulation was defined using the Autocad 3D module, without and with furniture, as it's shown in Figure 3a and 3b, respectively.

In the computational domain, the locations of the fresh air intake and exhaust air were placed according to the data taken from the site as follows:

- fresh air inlet grilles are positioned in the finishing layer of the living room floor at a distance of $30 \mathrm{~cm}$ from the wall, located on the south side of the building;

- the outlet air grilles are positioned in the kitchen space above the food preparation equipment (stove / electric hob), where significant releases of $\mathrm{CO}_{2}$, VOC and high relative humidity occur above the dishwasher and meal places areas.

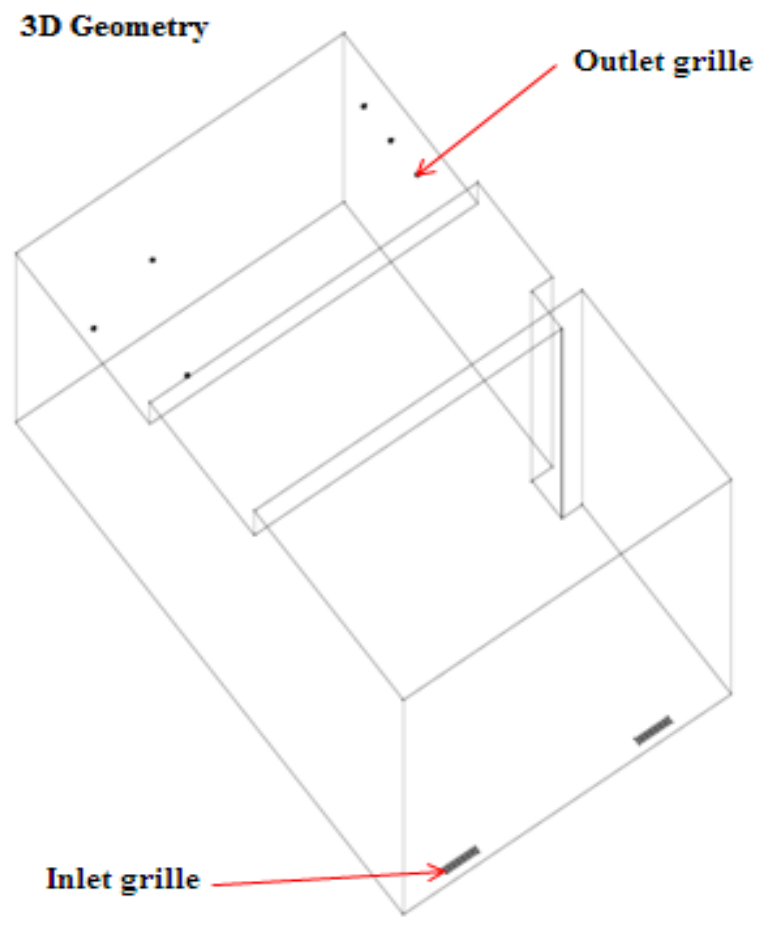

Fig. 3a. Simulation outline without furniture.

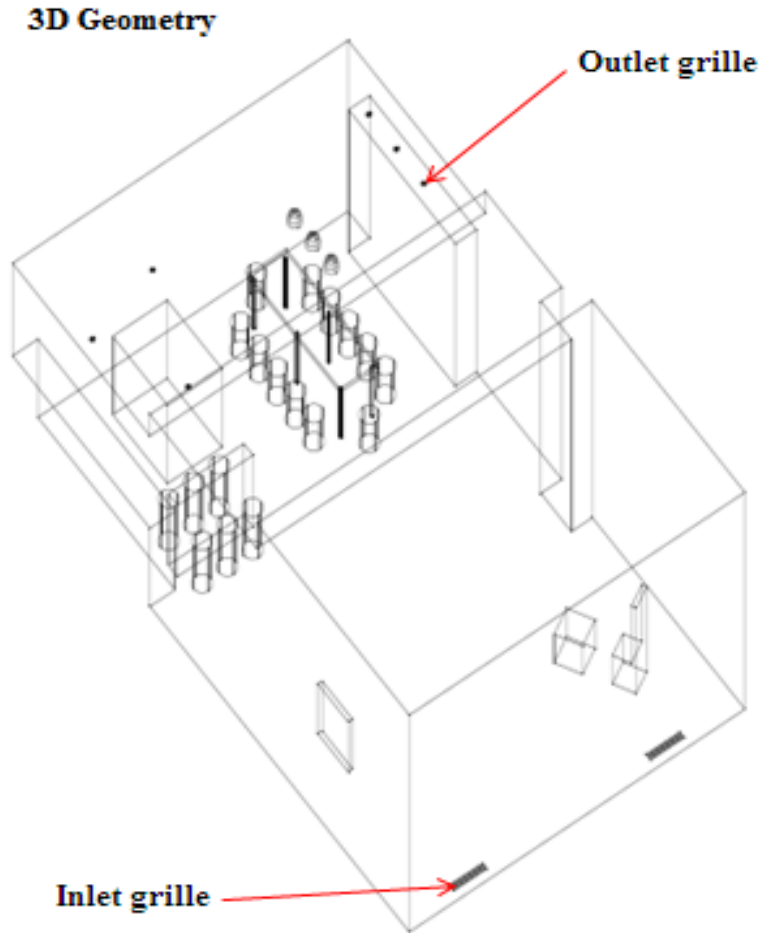

Fig. 3b. Simulation outline with furniture.

\subsection{Generating nodal network}

Numerical modeling and numerical simulation of air flow through the simulation field was achieved using the COMSOL MULTYPHISICS commercial software, version 3.5a. This application provides easy to use interfaces, algorithms for the efficient calculation, possibility of controlling the generation of complete nodal network and development environment for modeling the physical account for completely described of the coupled differential equation [11].

In modeling and simulating of the air flow within the simulation domain, after the nodal network was created, the k- $\varepsilon$ turbulence model was used together with the Navier-Stokes equation (1) as a motion equation:

$$
\rho \frac{\partial \mathbf{u}}{\partial \mathbf{t}}-\eta \nabla^{2} \mathbf{u}+\rho(\mathbf{u} * \nabla) \mathbf{u}+\nabla_{\mathbf{p}}=\mathbf{F}, \nabla * \mathbf{u}=\mathbf{0}
$$

where:

- $\quad \eta$ - dynamic viscosity, $\mathrm{N} \cdot \mathrm{s} / \mathrm{m}^{2}$

- $\quad \rho$ - density, $\mathrm{kg} / \mathrm{m}^{3}$,

- u - speed, $\mathrm{m} / \mathrm{s}$,

- $\quad \mathrm{p}$ - pressure, $\mathrm{N} / \mathrm{m}^{2}$,

- $\quad$ F - volume-gravitational force, $\mathrm{N} / \mathrm{m}^{3}$.

Prior to the computerized simulation of the fundamental governing equations, the following simplifying working hypotheses were established:

- stationary regime;

- Newtonian incompressible fluid (speeds, low pressures - no compressibility factor);

- isothermal jet, (the introduced air has the same temperature as the indoor air);

- constant temperature;

- mass forces are neglected (there are no pressure differences determined by the gravitational field); 
- adiabatic system (there is no heat transfer but just impulse);

- no internal heat sources.

For the discretion of the simulation domain, the finite element method was adopted, characterized by the fact that a certain virtual domain is subdivided into a number of finite elements, subdomains of variable size and shape that are interconnected by a discrete number of nodes.

The mode of dividing the simulation domain is uneven, the finite elements of the nodal network having the form of linear tetrahedron, it has a higher density of nodal network elements near the delimiting areas of the simulation domain, as shown in Figures $4 \mathrm{a}$ and $4 \mathrm{~b}$.

After meshing the computational domain, a finite number of elements resulted as follows:

24089 - without furniture and 34497 - with furniture.

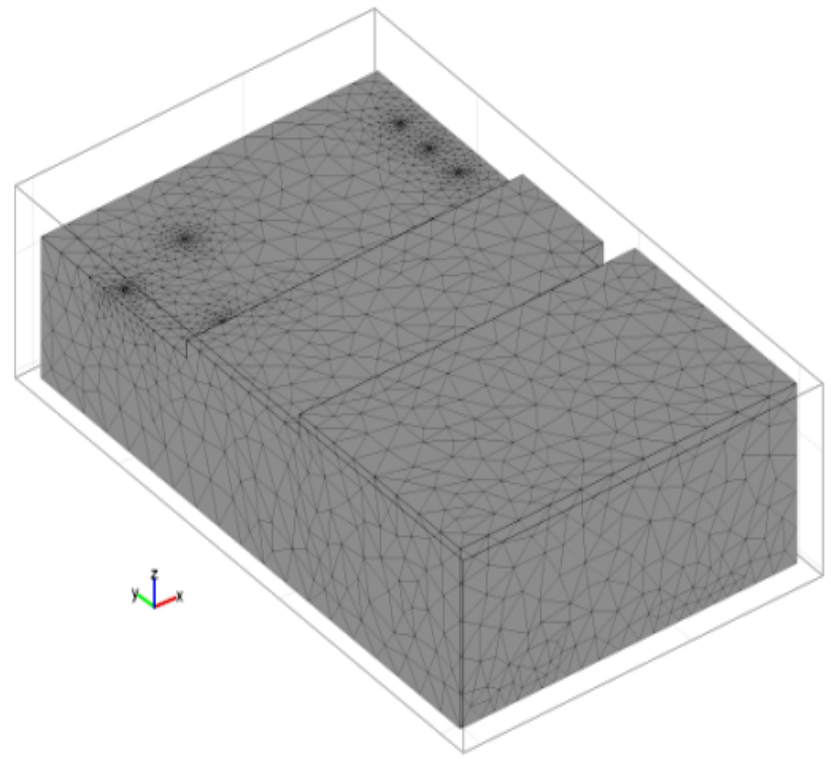

Fig. 4a. Nodal network - without furniture.

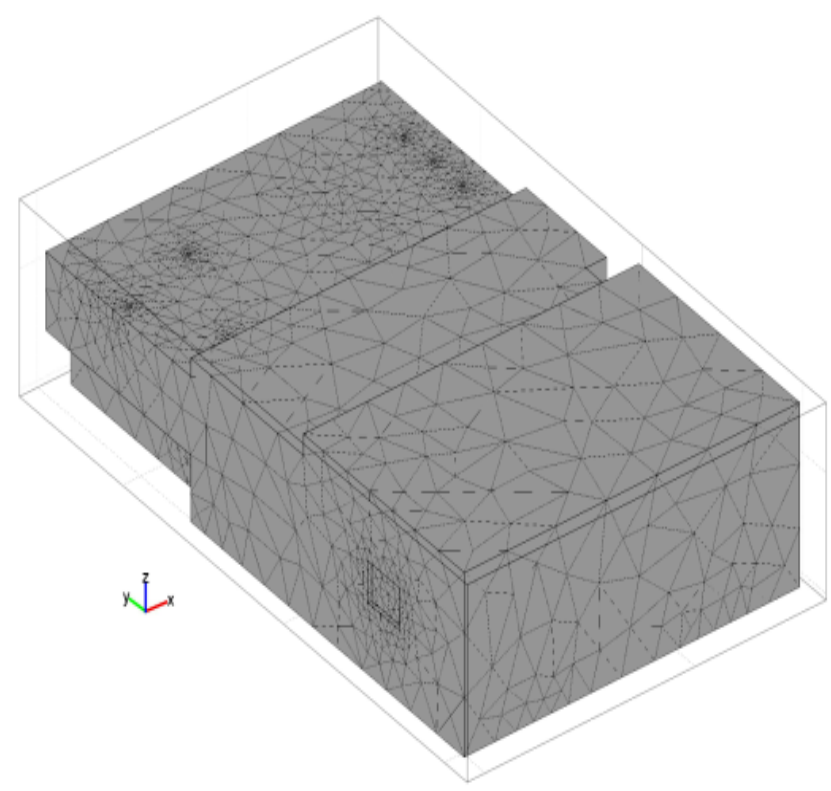

Fig. 4b. Nodal network - with furniture.

\section{Results and discussions}

By means of computerized simulation on the behavior of the working fluid through the simulation field for the two analyzed situations, with or without the presence of the furniture, under the conditions of the fresh air jet velocity introduced with the imposed values of $0.5 \mathrm{~m} / \mathrm{s}$, the behavior of the air flow was materialized through the below aspects:

- qualitative distribution: the current lines and the velocity vector,

- quantitative distribution: velocity contours.

The qualitative highlights of the flow of the working fluid through the distribution of the current lines, without the presence of the furniture, is shown in Figure 5.

When fresh air is introduced, it can be noticed that a turbulent air movement is generated in the adjacent area of the inlet grids, generated by passing the air jet at a rate of $0.5 \mathrm{~m} / \mathrm{s}$ through the grids. Upon exiting the turbulence zone, the air streams uniformly "wash" the other two sections of the simulation domain, freely orienting towards the suction and exhaust air grilles.

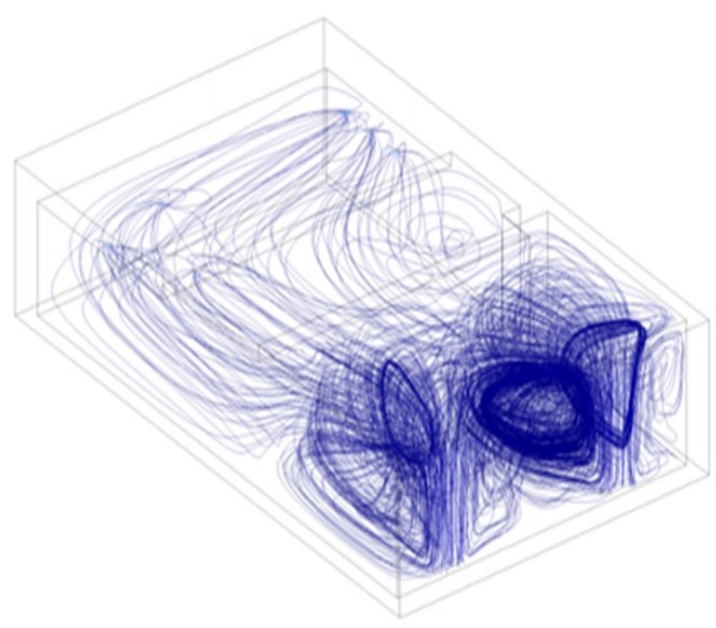

Fig. 5. Distribution of current lines, without furniture.

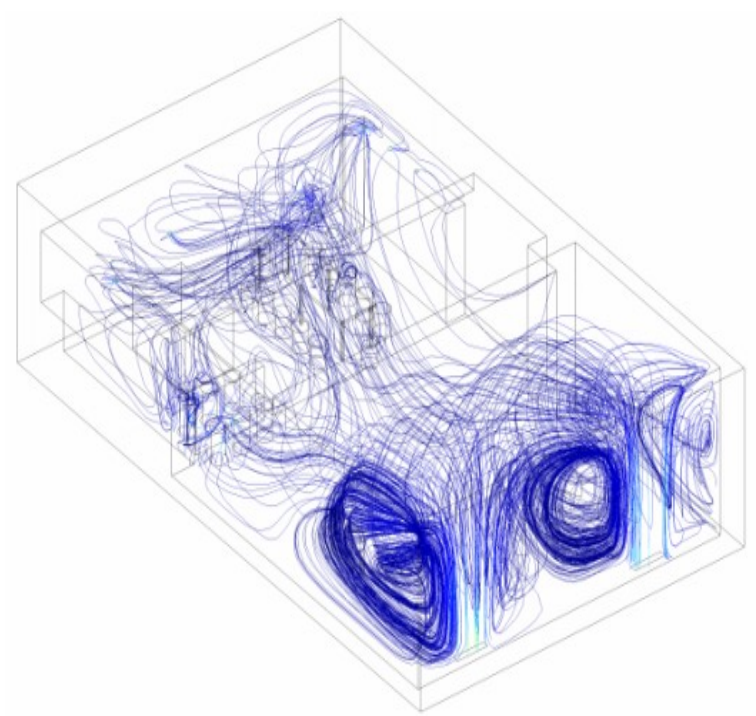

Fig. 6. Distribution of current lines, with furniture. 
In the presence of the furniture proposed by the designer, the distribution of the air currents is materialized by the distribution of the current lines as shown in Figure 6.

In this case, it is observed that in the area of the inlet orifices the airflow turbine configuration is slightly different in intensity compared to the previous case, noting that in the kitchen area there is a non-uniform distribution of the current lines due to the presence of the furniture in this space.

The second aspect of the qualitative evaluation of the flow of the working fluid through the simulation field is evidenced by the distribution of the velocity vectors, presented for the three cases of air velocities and air flow rates, in the two analyzed variants: with and without furniture.

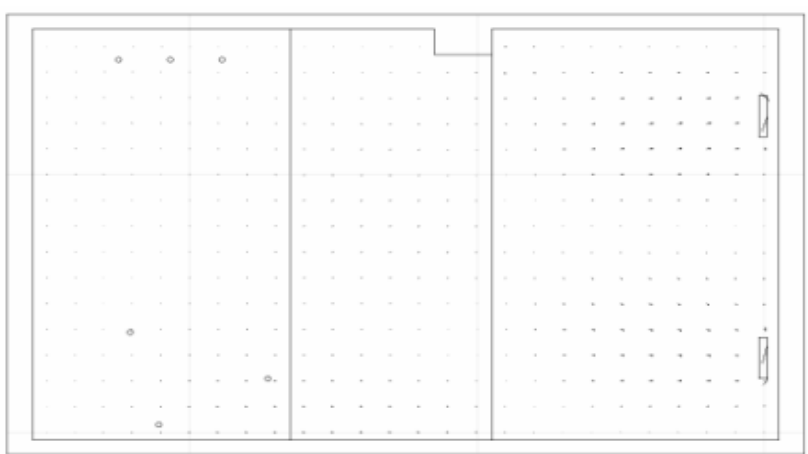

Fig. 7a. Distribution of the velocity vectors, without furniture Case $1:\left(\mathrm{v}_{1}=0,1 \mathrm{~m} / \mathrm{s}, \mathrm{V}_{1}=86 \mathrm{~m}^{3} / \mathrm{h}, \mathrm{h}=1,2 \mathrm{~m}\right)$.

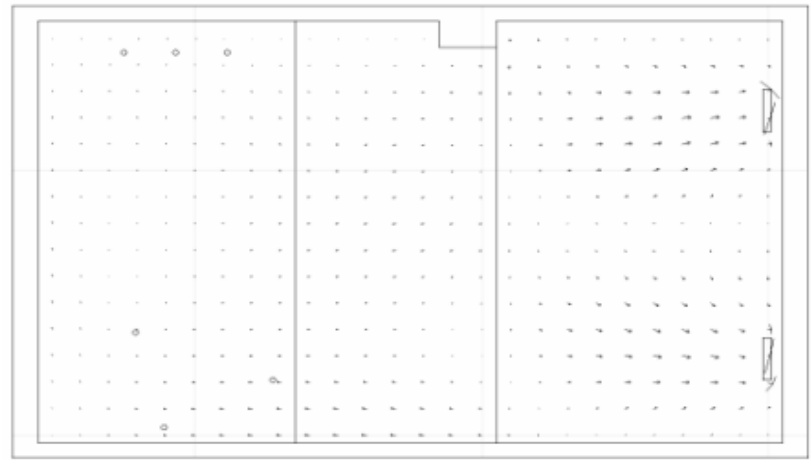

Fig. 7b. Distribution of the velocity vectors, without furniture Case $2:\left(v_{2}=0,2 \mathrm{~m} / \mathrm{s}, \mathrm{V}_{2}=172 \mathrm{~m}^{3} / \mathrm{h}, \mathrm{h}=1,2 \mathrm{~m}\right)$.

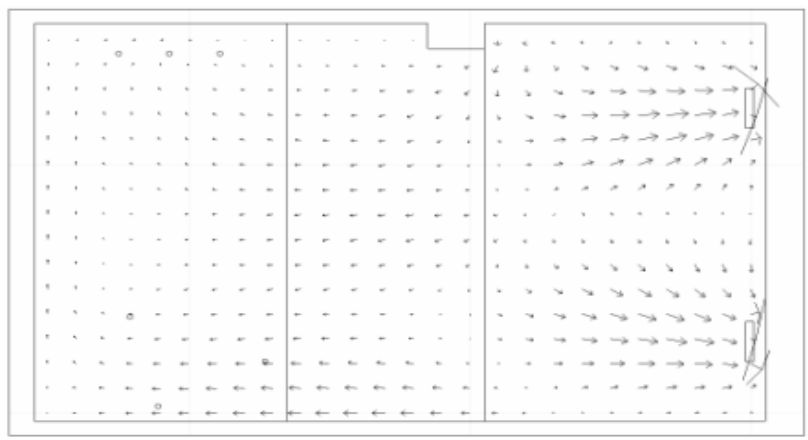

Fig. 7c. Distribution of the velocity vectors, without furniture Case $3:\left(v_{3}=0,5 \mathrm{~m} / \mathrm{s}, \mathrm{V}_{3}=215 \mathrm{~m}^{3} / \mathrm{h}, \mathrm{h}=1,2 \mathrm{~m}\right)$.

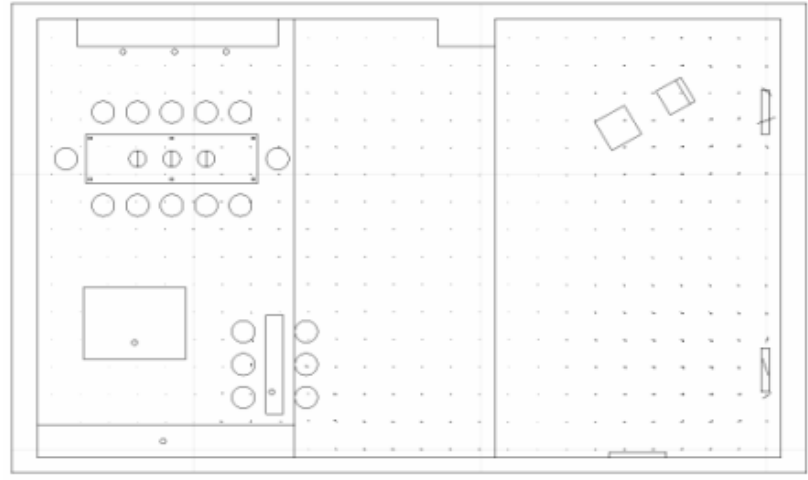

Fig. 8a. Distribution of the velocity vectors, with furniture Case $1:\left(\mathrm{v}_{1}=0,1 \mathrm{~m} / \mathrm{s}, \mathrm{V}_{1}=86 \mathrm{~m}^{3} / \mathrm{h}, \mathrm{h}=1,2 \mathrm{~m}\right)$.

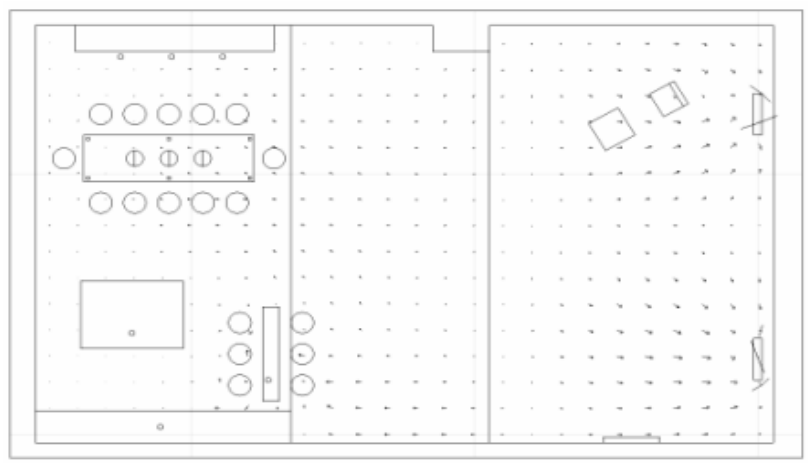

Fig. 8b. Distribution of the velocity vectors, with furniture Case $2:\left(\mathrm{v}_{2}=0,2 \mathrm{~m} / \mathrm{s}, \mathrm{V}_{2}=172 \mathrm{~m}^{3} / \mathrm{h}, \mathrm{h}=1,2 \mathrm{~m}\right)$.

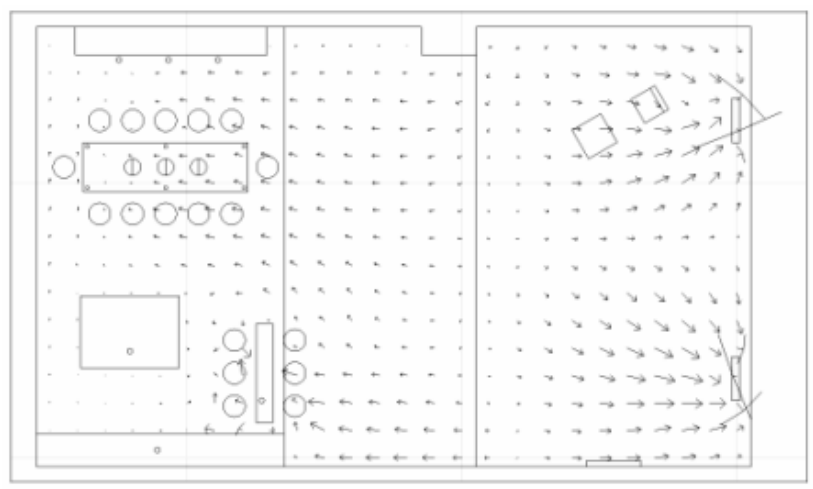

Fig. 8c. Distribution of the velocity vectors, with furniture Case $3:\left(v_{3}=0,5 \mathrm{~m} / \mathrm{s}, \mathrm{V}_{3}=215 \mathrm{~m}^{3} / \mathrm{h}, \mathrm{h}=1,2 \mathrm{~m}\right)$.

If we consider the characteristic horizontal section located at a height of $1.2 \mathrm{~m}$ from the floor, which coincides with a work plan specific to the activities carried out by the occupants in the seated position, the distribution of the velocity vectors will show as in Figures $7 \mathrm{a}, 7 \mathrm{~b}$ and $7 \mathrm{c}$ for the case without furniture and as in Figures $8 \mathrm{a}, 8 \mathrm{~b}$ and $8 \mathrm{c}$ for the case with furniture.

From the images shown in figure $7 \mathrm{a}, 7 \mathrm{~b}$ and $7 \mathrm{c}$ it is noted that with the increase of the fresh air input the velocity vectors become more and more visible in all the sections of the simulation domain occupying the entire analyzed space. In the second case, in Figures 8, compared to the previous case presented, there are some areas of furniture in the kitchen in which the velocity vectors change their direction as a result of encountering these obstacles. 
The third aspect of the quantitative assessment of the flow of the working fluid through the simulation field is evidenced by the distribution of the velocity contours analyzed for the two variants (with or without furniture) for the same fresh air inlet speeds $(\mathrm{v} 1=0.1 \mathrm{~m} / \mathrm{s}, \mathrm{v} 2=0.2$ $\mathrm{m} / \mathrm{s}$ and $\mathrm{v} 5=0.5 \mathrm{~m} / \mathrm{s}$ ), considering two axial reference planes for fresh air intake and for evacuation of vicious air.

In the images presented in figure $9 \mathrm{a}, 9 \mathrm{~b}$ and $9 \mathrm{c}$ it is observed that when fresh air is introduced into the axial vertical plane on the introduction grids with higher velocity, the distribution of the air velocity contours is increased.

In the presence of the furniture in the simulation field, it is observed that the amplitude of the velocity contours (fields) is relatively lower than in the case without furniture, Figure 10a, 10b and 10c.
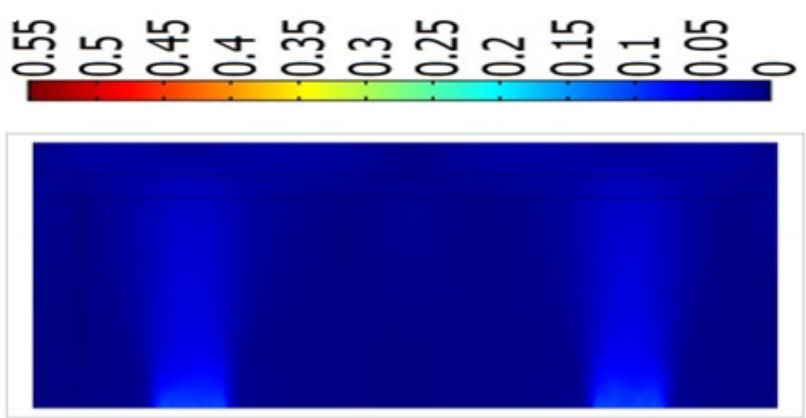

Fig. 9a. Distribution of the velocity contours, inlet grilles, without furniture. Case $1:\left(\mathrm{v}_{1}=0,1 \mathrm{~m} / \mathrm{s}, \mathrm{V}_{1}=86 \mathrm{~m}^{3} / \mathrm{h}\right)$.
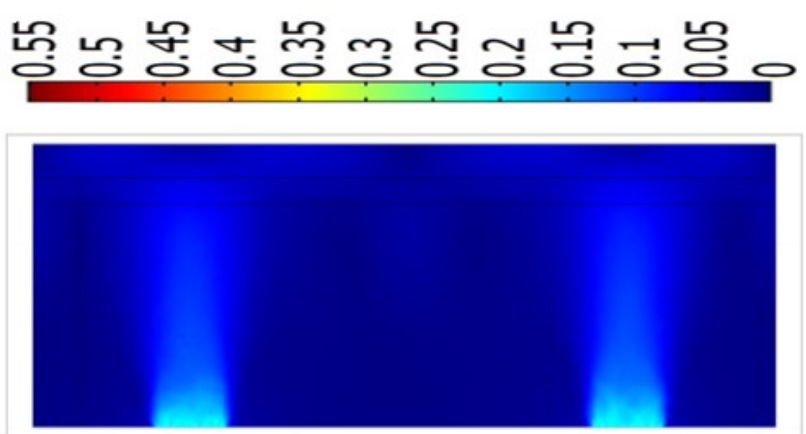

Fig. 9b. Distribution of the velocity contours, inlet grilles, without furniture. Case $2:\left(\mathrm{v}_{2}=0,2 \mathrm{~m} / \mathrm{s}, \mathrm{V}_{2}=172 \mathrm{~m}^{3} / \mathrm{h}\right)$.
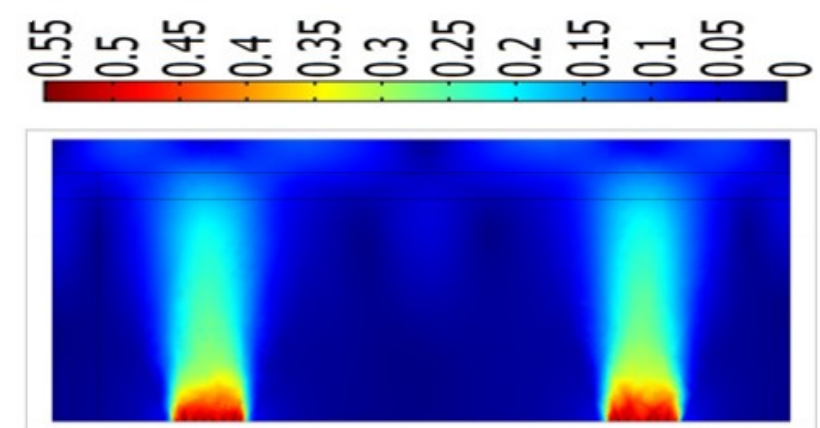

Fig. 9c. Distribution of the velocity contours, inlet grilles, without furniture. Case $3:\left(\mathrm{v}_{3}=0,5 \mathrm{~m} / \mathrm{s}, \mathrm{V}_{3}=215 \mathrm{~m}^{3} / \mathrm{h}\right)$.
The distribution of the velocity contours in the case without furniture, under the conditions of the three fresh air inlet rates in the axial plane corresponding to the inlet grilles is shown in Figure 9a, 9b and 9c.

The distribution of the velocity contours without the presence of the furniture, which occurs under the conditions of the three fresh air inlet speeds, in the axial plane corresponding to the exhaust grilles is shown in Figure 11a, 11b and 11c.

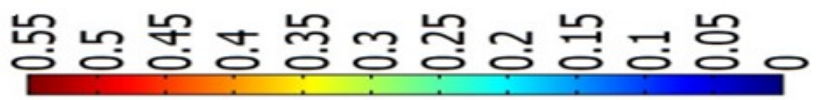

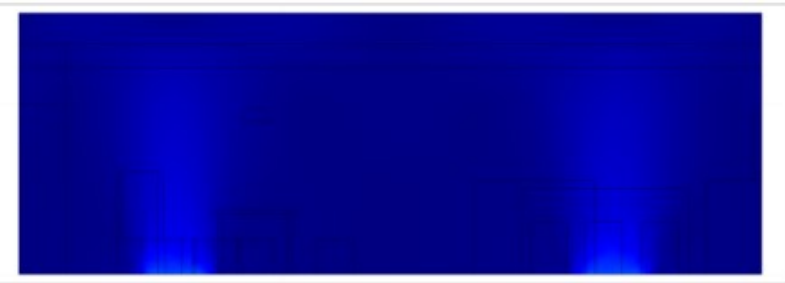

Fig. 10a. Distribution of the velocity contours, inlet grilles, with furniture. Case 1: $\left(\mathrm{v}_{1}=0,1 \mathrm{~m} / \mathrm{s}, \mathrm{V}_{1}=86 \mathrm{~m}^{3} / \mathrm{h}\right)$.

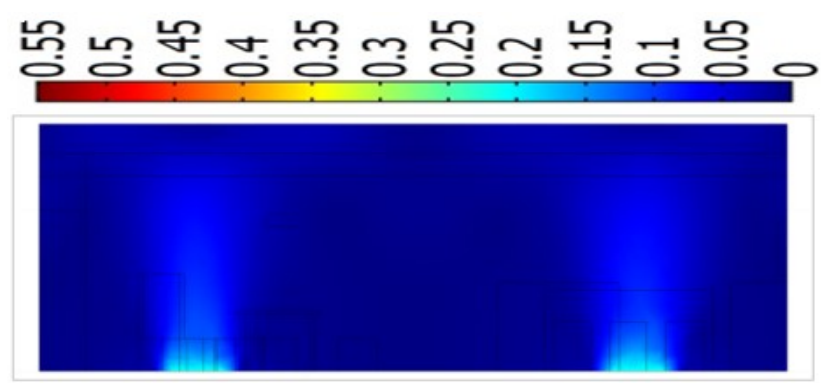

Fig. 10b. Distribution of the velocity contours, inlet grilles, with furniture Case 2: $\left(\mathrm{v}_{2}=0,2 \mathrm{~m} / \mathrm{s}, \mathrm{V}_{2}=172 \mathrm{~m}^{3} / \mathrm{h}\right)$.

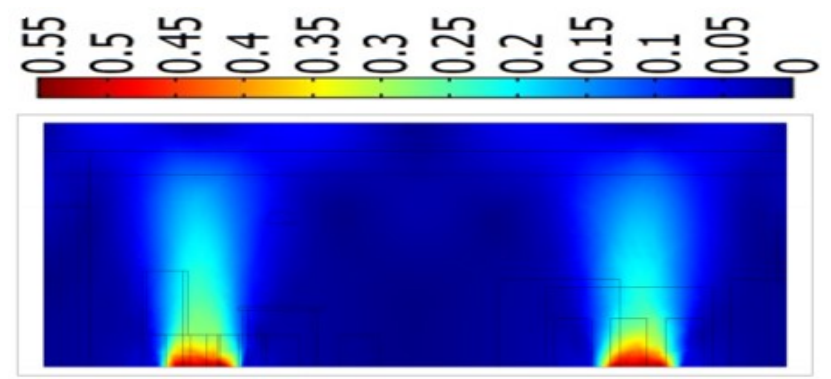

Fig. 10c. Distribution of the velocity contours, inlet grilles, with furniture Case 3: $\left(\mathrm{v}_{3}=0,5 \mathrm{~m} / \mathrm{s}, \mathrm{V}_{3}=215 \mathrm{~m}^{3} / \mathrm{h}\right)$.

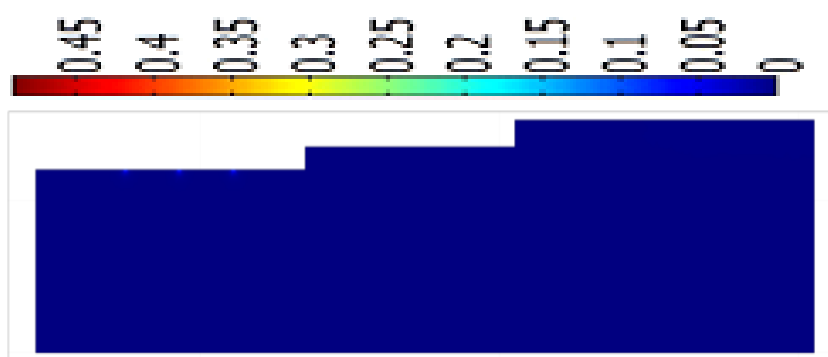

Fig. 11a. Distribution of the velocity contours, outlet grilles, without furniture. Case $1:\left(\mathrm{v}_{1}=0,1 \mathrm{~m} / \mathrm{s}, \mathrm{V}_{1}=86 \mathrm{~m}^{3} / \mathrm{h}\right)$. 


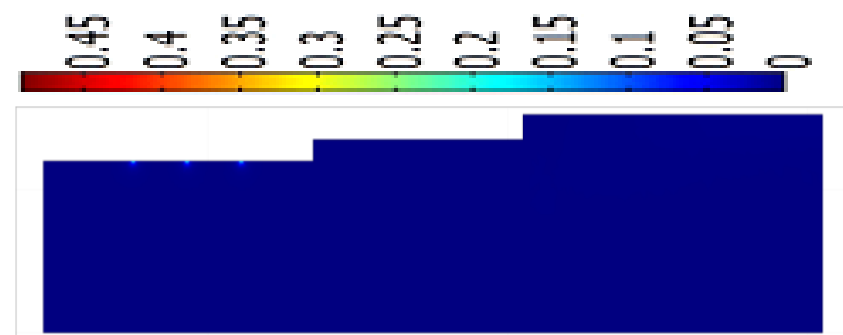

Fig. 11b. Distribution of the velocity contours, outlet grilles, without furniture. Case $2:\left(\mathrm{v}_{2}=0,2 \mathrm{~m} / \mathrm{s}, \mathrm{V}_{2}=172 \mathrm{~m}^{3} / \mathrm{h}\right)$.

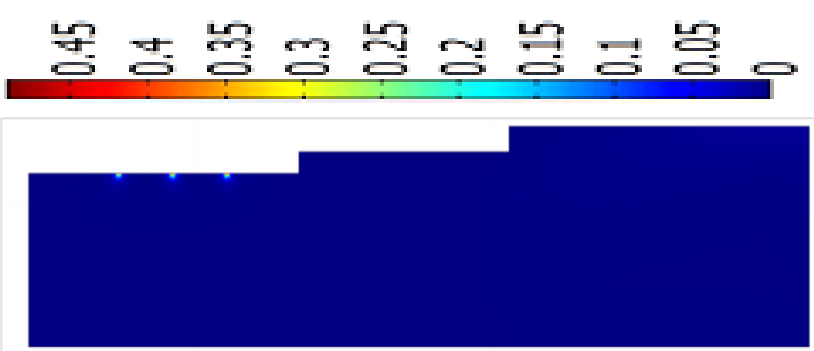

Fig. 11c. Distribution of the velocity contours, outlet grilles, without furniture. Case $3:\left(\mathrm{v}_{3}=0,5 \mathrm{~m} / \mathrm{s}, \mathrm{V}_{3}=215 \mathrm{~m}^{3} / \mathrm{h}\right)$.

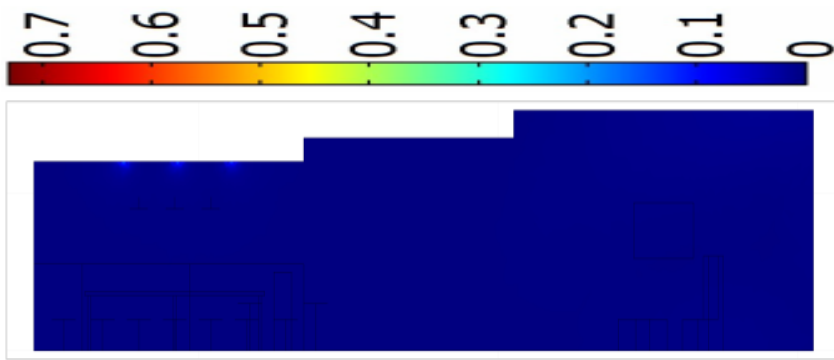

Fig. 12a. Distribution of the velocity contours, outlet grilles, with furniture. Case 1: $\left(\mathrm{v}_{1}=0,1 \mathrm{~m} / \mathrm{s}, \mathrm{V}_{1}=86 \mathrm{~m}^{3} / \mathrm{h}\right)$.

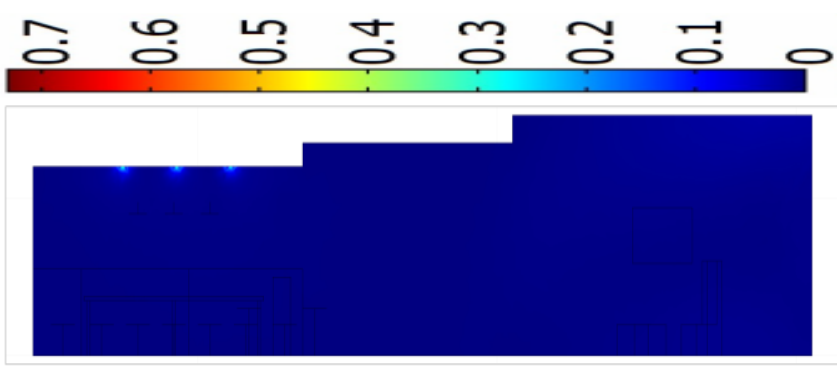

Fig. 12b. Distribution of the velocity contours, outlet grilles, with furniture. Case 2: $\left(\mathrm{v}_{2}=0,2 \mathrm{~m} / \mathrm{s}, \mathrm{V}_{2}=172 \mathrm{~m}^{3} / \mathrm{h}\right)$.

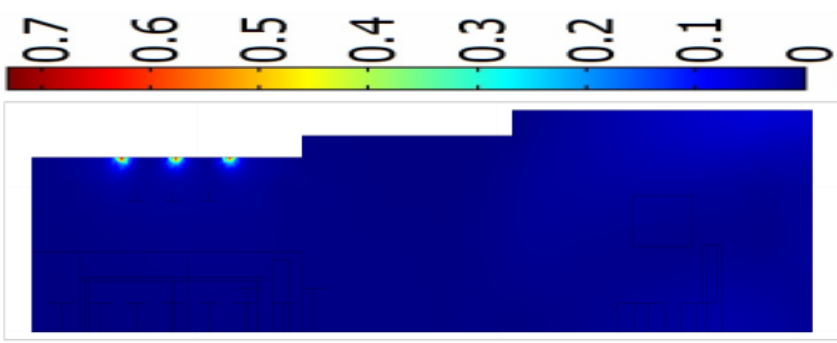

Fig. 12c. Distribution of the velocity contours, outlet grilles, with furniture. Case $3-\left(\mathrm{v}_{3}=0,5 \mathrm{~m} / \mathrm{s}, \mathrm{V}_{3}=215 \mathrm{~m}^{3} / \mathrm{h}\right)$.

In the case of exhaust grilles, it is ascertained that, with the increase of the fresh air inlet speed, the variation of the velocity contours in the vicinity of the exhaust grilles is slow.

In the presence of furniture in the simulation field, the distribution of the velocity contours in the grille area is shown as in the Figures 12a, 12b and 12c.

In this case, the distribution of the contours of the velocity of the air currents becomes better outlined, it being noted that in the section of the outlet grids there can be encountered higher speed values than the ones of introduction, which result from the presence of the furniture in the area of evacuation grille.

\section{Conclusions}

Following the case studies on the distribution of air currents within the simulation domain materialized by qualitative evaluation by the distribution of current lines and velocity vectors and by the distribution of the contours of the velocity, the following conclusions can be drawn:

- the presence of furniture has an insignificant influence on the qualitative distribution of air velocity;

- in the occupied area, the speed of the air falls within the limits provided by the occupants' comfort standards;

- the occupants' comfort is not affected by the higher air velocity values in the air inlet zones or by the air velocities present in the exhaust grille areas.

The quality and performance of the heat recovery ventilation system imposed by the requirements of the passive house standard are of utmost importance both to ensure and maintain thermal comfort in the parameters and the hydro-thermal stability of the building as well as to the energy performance level of the building.

\section{References}

1. ***, Passive-On Project. Design guidelines. Policy mechanism, www.passive-on.org/en

2. ***, Pass-net Project, www.pass-net.net/index.htm

3. ***, PassREg Project, Passive House Regions with Renewable Energies, www.passreg.eu

4. W. Feist, J. Schnieders, V. Dorer, A. Haas, Energy and Buildings, Elsevier, 37, (2005)

5. ***, Passipedia - The Passive House Resource, www.passipedia.org

6. F. Van Dijken, J. R. Balvers J R, and A. C. Boerstra, Proceedings of the 12th Int. Conf. on Indoor Air Quality and Climate, (2011)

7. H. Manz., H. Huber, A.Schalin, A. Weber, M. Ferrazzini, M. Studer, Energy \& Build., 31 (2000)

8. R. Jensen, C. Brunsgard, Proceedings of $12^{\text {th }}$ Int. Passive House Conference, Nuremburg, (2008)

9. ***, COMSOL Multiphysocs - User's Guide, (2006)

10. ***, Pluggit - The residential ventilation, www.pluggit.com

11. ***, Understand, Predict, and Optimize PhysicsBased Designs and Processes, www.comsol.com/comsol-multiphysics 